\title{
Understanding Emotions in Electronic Auctions: Insights from Neurophysiology
}

\author{
Marc T. P. Adam and Jan Krämer
}

\begin{abstract}
The design of electronic auction platforms is an important field of electronic commerce research. It requires not only a profound understanding of the role of human cognition in human bidding behavior but also of the role of human affect. In this chapter, we focus specifically on the emotional aspects of human bidding behavior and the results of empirical studies that have employed neurophysiological measurements in this regard. By synthesizing the results of these studies, we are able to provide a coherent picture of the role of affective processes in human bidding behavior along four distinct theoretical pathways.
\end{abstract}

\section{Introduction}

Electronic auctions (i.e., electronic auction marketplaces) are information systems that facilitate and structure the exchange of products and services between several potential buyers and sellers. In practice, electronic auctions have been employed for a wide range of goods and services, such as commodities (e.g., Internet consumer auction markets, such as eBay.com), perishable goods (e.g., Dutch flower markets, such as by Royal FloraHolland), consumer services (e.g., procurement auction markets, such as myhammer.com), or property rights (e.g., financial double auction markets such as NASDAQ). In this vein, a large share of our private and commercial economic activity is being organized through electronic auctions today (Adam et al. 2017; Ku et al. 2005).

Previous research in information systems, economics, and psychology has shown that the design of electronic auctions has a tremendous impact on the auction

M. T. P. Adam

College of Engineering, Science and Environment, The University of Newcastle, Callaghan, Australia

e-mail: marc.adam@newcastle.edu.au

J. Krämer $(\square)$

University of Passau, Passau, Germany

e-mail: jan.kraemer@uni-passau.de 
outcome, even-or particularly-when theory did not suggest that there should be differences. For example, the auction outcome was found to be affected by the interface design (Adam et al. 2016), the auction mechanism used (Hariharan et al. 2016), the speed at which prices are incremented or decremented (Carare and Rothkopf 2005; Katok and Kwasnica 2008), and other elements of time pressure inherent to auctions (Ariely and Simonson 2003; Ku et al. 2005). In seeking to better understand these effects, scholars increasingly recognize the role of the bidders' emotions, such as the "joy of winning" or the "fear of losing" (Delgado et al. 2008). Furthermore, a bidder's emotional state may also culminate in a state of "competitive arousal" that is elicited during auction participation ( $\mathrm{Ku}$ et al. 2005).

Despite these important and insightful findings, previous research on the role of emotions in electronic auctions is rather scattered throughout the economic, psychology, and IS disciplines. In 2011, Adam et al. (2011b) proposed an integrative theoretical framework for emotional bidding that aimed to provide a unified view for the dynamic influence of emotions on human bidding behavior. Thereby, the authors not only considered the classical economic perspective on human bidding behavior but also the role that a bidder's immediate emotions (e.g., frustration, joy, regret) as well as their overall emotional state (i.e., overall level and valence of emotional processing) may play in bidding. Almost 10 years later, we map the propositions of this framework to findings from empirical research. Thereby, we specifically focus on results taking into account neurophysiological measurements (e.g., brain imaging, heart rate, skin conductance) due to their ability to provide unique insights into the unconscious processing of human emotion.

\section{Theoretical Background}

\subsection{Affective Processing and Emotions}

Affective processes and emotions play an important role in how users perceive and experience information systems. Information systems can trigger affective processes in the user, which through the vehicle of emotion shape the users' attitudes, beliefs, and response tendencies. With or without conscious awareness, these processes can ultimately have an influence on user behavior. As famously stated by Bradley (2007, p. 602), "it sometimes seems that there are as many definitions [of emotion] as there are investigators." Reflecting a rather general understanding of emotions in psychological literature, the term emotion can be roughly defined as a subjectively experienced state that can be described qualitatively and is accompanied by changes in feeling, physiology, and expression (Myers 2004). Thus, a subjectively experienced feeling is only a part of the broader concept of emotion, which also comprises objectively observable changes, for example, in neurophysiology.

In the present work, we build on the conceptualization by Rick and Lowenstein (2008) and distinguish between a person's (1) immediate emotions and (2) overall 
emotional state. Within this conceptualization, an immediate emotion refers to a short burst of emotional experience which is elicited by an internal (e.g., fear in response to thinking about an unpleasant event) and/or external stimulation (e.g., joy in response to learning about a discount). By contrast, the emotional state refers to a person's overall state of emotions and thereby canalizes the influence of emotional reactions. Importantly, while immediate emotions are transient, the emotional state is ongoing and "the individual is never without being in some emotional state" (Zajonc 1984, p. 21).

\subsection{Framework for Emotional Bidding}

In the context of electronic auctions, affective processes can be triggered by the design of the user interface as well as by the underlying auction mechanism. Adam et al. (2011b) introduced an integrative theoretical framework along with a set of specific propositions to conceptualize the emergence and impact of affective processes in electronic auctions (see Fig. 1). The framework builds on the previously mentioned conceptualization by Rick and Loewenstein (2008) that distinguishes between immediate emotions and a person's overall emotional state.

The top row (Auction System \& Environment $\rightarrow$ Auction Outcome) depicts the traditional, economic cause-and-effect relationship of auction theory (McAfee and McMillan 1987). Assuming an emotionless homo economicus, who is fully rational and has the ability to assess all available information and possible strategic interactions, the (equilibrium) bidding strategy is determined ex-ante and depends only on the auction system and environment (i.e., the set of rules governing the auction, the number of competitors, etc.). The bidding strategy is a master plan for every possible contingency that may occur during the auction process, and thus,

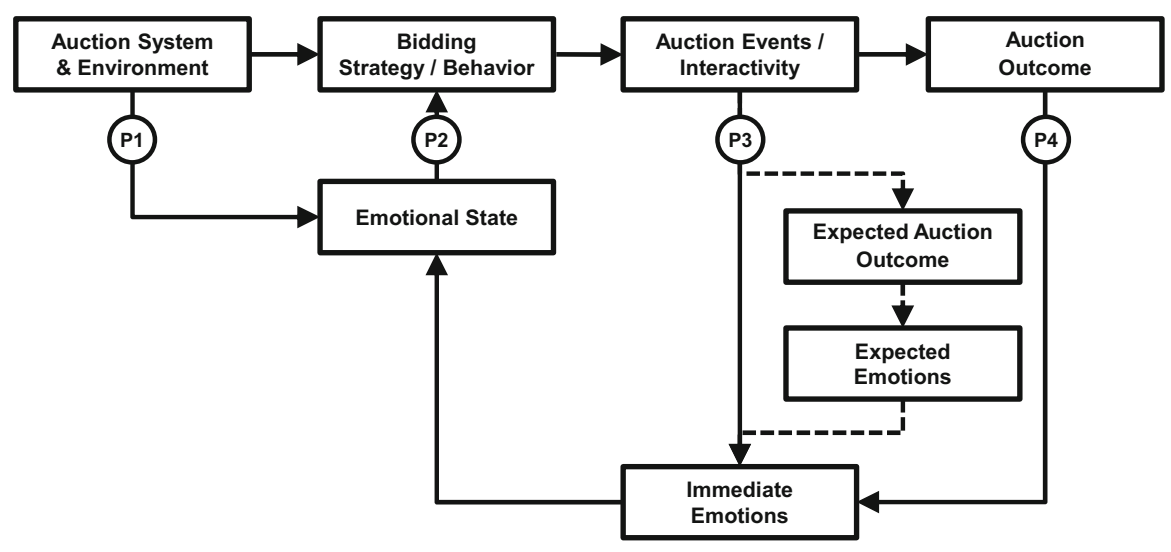

Fig. 1 Framework for emotional bidding (adapted from Adam et al. [2011b]) 
from a purely game-theoretic point of view, there is no need to modify the bidding strategy during the auction. Hence, under the traditional economic view, the causeand-effect relationship between the auction system and environment and the auction outcome is unidirectional and does not contain feedback loops.

Below the top row, the framework takes into account the emergence and impact of affective processes on human bidding behavior and auction outcomes. In this vein, the framework explicitly takes into account psychological feedback loops that are not considered in the traditional economic perspective. In other words, the assumption of a homo economicus is thereby complemented by the assumption of a homo emoticus (Sigmund et al. 2002). The specific cause-and-effect relationships between a bidder's emotional state (i.e., their overall arousal and valence of affective processing) and their immediate emotions (e.g., joy of winning, frustration of losing) are made explicit by a set of theoretical propositions. ${ }^{1}$ While the original framework contains a total of six propositions, in the present chapter we focus specifically on a simplified subset of four propositions:

Proposition 1 (P1): The auction system and environment influences a bidder's overall emotional state.

Proposition 2 (P2): A bidder's current emotional state has an influence on their bidding behavior

Proposition 3 (P3): Auction events affect the emergence of immediate emotions

Proposition 4 (P4): The auction outcome affects the emergence of immediate emotions

\subsection{Neurophysiological Measurements}

The field of NeuroIS draws upon the theories, methods, and tools in neurophysiology to advance the design, evaluation, and understanding of information systems (Riedl et al. 2014). This includes both techniques that measure brain activation such as functional magnetic resonance imaging (fMRI), electroencephalography (EEG), and positron emission tomography (PET) and physiological measurements such as electrocardiography (ECG), facial electromyography (EMG), and skin conductance (SC) measurements. By linking these neurophysiological measurements to users' perceptions and behaviors, researchers can investigate the role of human affective processing in human-computer interaction (Adam et al. 2011a; Hariharan et al. 2017; Jung et al. 2017).

\footnotetext{
${ }^{1}$ Specifically, the original framework also considers a more nuanced interplay between expected and immediate emotions. However, to the best of our knowledge, there is currently no research available that provides insight into these.
} 
As for the context of affective processing, it is important to highlight that neurophysiological measures provide insight into two important dimensions of emotion: valence and arousal. According to the circumplex model of emotion (Russel 1980), the arousal dimension refers to the general intensity of emotion and ranges from calm to excited. In contrast, the valence dimension refers to whether the emotion is perceived as pleasant or unpleasant. By applying these measurements in the context of electronic auctions, this information provides important insights into a bidder's overall emotional state (e.g., the level of competitive arousal during auction participation) and the emergence of specific immediate emotions (e.g., the intensity of the joy of winning and the frustration of losing).

\section{Empirical Results}

In the following, we map the results of empirical studies to the four propositions of the framework shown in Fig. 1. Thereby, we particularly focus on evidence from studies employing neurophysiological measurements. Table 1 provides a summary of this mapping.

\subsection{Impact of the Auction System and Environment on a Bidder's Current Emotional State (P1)}

The auction system and environment includes a multiplicity of factors that may affect a bidder's emotional state. As noted by Adam et al. (2019), this could potentially even relate to seemingly irrelevant aspects such as whether the bidder had recently been to the gym or consumed an espresso. Conceptually, we can distinguish factors that are integral to the auction context and incidental factors that are outside the auction context. Providing support for P1, studies using neurophysiological measurements showed that both of these categories can affect a bidder's emotional state.

In terms of integral factors, one stream of literature has considered the speed of price changes in ascending and descending clock auctions. Specifically, it was shown that when increasing the clock speed from $5 \mathrm{~s}$ per price change to $0.5 \mathrm{~s}$ per price change, bidders exhibited higher heart rates (Adam et al. 2012, 2015). Further, research showed that competing with other human bidders instead of computerized bidders is another important driver for arousal in auctions (Adam et al. 2015; Teubner et al. 2015). In terms of incidental factors, research has shown that seemingly unrelated imagery in the auction environment affects a bidder's current emotional state. For instance, Adam et al. (2016) showed that competitive images (e.g., pictures of competitive sports) created a different emotional state in bidders than community images (e.g., pictures of family scenes). 
Table 1 Mapping between propositions and empirical results

\begin{tabular}{|c|c|}
\hline Proposition & Empirical result \\
\hline \multirow[t]{3}{*}{$\begin{array}{l}\text { P1: The auction system and environment } \\
\text { influences a bidder's overall emotional state }\end{array}$} & $\begin{array}{l}\text { Faster clock speeds in clock auctions are } \\
\text { linked to higher arousal (heart rates) (Adam } \\
\text { et al. 2012, 2015) }\end{array}$ \\
\hline & $\begin{array}{l}\text { Affective imagery in the auction environment } \\
\text { increases bidders' overall arousal (Adam } \\
\text { et al. 2016, 2019) }\end{array}$ \\
\hline & $\begin{array}{l}\text { Descending clock auctions induce higher } \\
\text { arousal (heart rates) than ascending clock } \\
\text { auctions (Smith and Dickhaut 2005) }\end{array}$ \\
\hline \multirow[t]{2}{*}{$\begin{array}{l}\text { P2: A bidder's current emotional state has an } \\
\text { influence on their bidding behavior }\end{array}$} & $\begin{array}{l}\text { Higher overall arousal (heart rates) is linked } \\
\text { to higher (/lower) bids in ascending } \\
\text { (/descending) clock auctions (Adam et al. } \\
2012,2015 \text { ) }\end{array}$ \\
\hline & $\begin{array}{l}\text { Higher arousal in sealed-bid auctions is } \\
\text { linked to higher (/lower) bids in common } \\
\text { value (/private value) settings (Adam et al. } \\
\text { 2019; Teubner et al. 2015) }\end{array}$ \\
\hline \multirow[t]{2}{*}{$\begin{array}{l}\text { P3: Auction events affect the emergence of } \\
\text { immediate emotions }\end{array}$} & $\begin{array}{l}\text { Submitting a sealed bid triggers skin } \\
\text { conductance responses, the intensity of } \\
\text { which is positively related to the amount of } \\
\text { money at stake (Teubner et al. 2015) }\end{array}$ \\
\hline & $\begin{array}{l}\text { Placing a bid under high time pressure } \\
\text { induces weaker immediate emotions than } \\
\text { placing a bid under low time pressure (Adam } \\
\text { 2010) }\end{array}$ \\
\hline \multirow[t]{3}{*}{$\begin{array}{l}\text { P4: The auction outcome affects the } \\
\text { emergence of immediate emotions }\end{array}$} & $\begin{array}{l}\text { Winning a sealed-bid auction induces } \\
\text { stronger immediate emotions (brain activity, } \\
\text { skin conductance) than losing it (Astor et al. } \\
\text { 2013a; Teubner et al. 2015; van den Bos et al. } \\
\text { 2013) }\end{array}$ \\
\hline & $\begin{array}{l}\text { Losing a descending clock auction induces a } \\
\text { stronger skin conductance response than } \\
\text { winning it (Adam et al. 2012) }\end{array}$ \\
\hline & $\begin{array}{l}\text { Losing a sealed-bid auction triggers stronger } \\
\text { immediate emotions (brain activity in } \\
\text { striatum) than losing an equivalent lottery } \\
\text { removed from the auction context (Delgado } \\
\text { et al. 2008) }\end{array}$ \\
\hline
\end{tabular}

\subsection{Impact of a Bidder's Current Emotional State on Their Bidding Behavior (P2)}

Researchers in psychology have long conjectured that factors in the auction system and environment may not only change a bidder's emotional state but that this change in the emotional state may also affect their bidding behavior ( $\mathrm{Ku}$ et al. 2005; Murnighan 2002). In the literature, this impact of the emotional state on 
bidding behavior is often referred to as auction fever. Referring to the visceral nature of auction fever, Murnighan (2002, p. 63) conjectured that during auction fever bidders' "adrenaline starts to rush, their emotions block their ability to think clearly, and they end up bidding more than they ever envisioned." Providing support for P2, studies using neurophysiological measurements have linked changes in a bidder's emotional state to their bidding behavior.

Focusing on the role of clock speeds in ascending and descending clock auctions, Adam et al. (2015) and Adam et al. (2012) showed that the way in which the emotional state affects the bidding behavior depends on the auction mechanisms. While in ascending auctions higher arousal is associated with higher bids, the reverse is true for descending auctions. Here, higher arousal is associated with lower bids (Adam et al. 2012). Further research showed that the link between a bidder's emotional state and their bidding behavior does not only hold for dynamic auctions but also for static, sealed-bid auctions (Adam et al. 2016, 2019; Teubner et al. 2015). Importantly, however, these studies found that the direction of the relationship depends on the underlying value model. In sealed-bid settings, for instance, higher arousal was associated with higher bids in common value settings (Adam et al. 2019; van den Bos et al. 2013), whereas the reverse was true for independent private value settings (Adam et al. 2016; Teubner et al. 2015). These differences between ascending and descending and between common and private value settings, respectively, can be explained by the notion of arousal's risk-promoting effects. Placing higher bids in common value auctions is associated with a higher risk of paying too much. In first-price independent-private value auctions, risk-averse bidders would generally place higher bids, because, by definition, risk averseness means that a bidder is willing to accept a lower profit when the outcome is more certain. By bidding higher, winning the auction becomes more certain; in reverse, this means that a risk-taking bidder has a tendency to bid lower in a first-price auction, because this offers a higher profit in case the auction is won, but entails a higher risk of not winning the auction.

\subsection{Immediate Emotions in Response to Auction Events (P3)}

Only a few neurophysiological studies have investigated the emergence of immediate emotions in response to auction events. However, the limited studies that have been conducted provide support for the link expressed in P3. Specifically, Teubner et al. (2015) measured the bidders' skin conductance responses in response to submitting a bid and waiting for the result. Their results showed that both of these events trigger an immediate emotion, the intensity of which increases with higher amounts of money at stake. Complementarily, Adam (2010) found that placing a bid under high time pressure induces weaker immediate emotions in terms of skin conductance responses than placing a bid under low time pressure. 


\subsection{Immediate Emotions in Response to Auction Outcome (P4)}

The announcement of the auction outcome is arguably the single most anticipated event in any auction. After all, the outcome of an auction provides clarity in terms of resource allocation (who gets what) and prices (who pays what). Providing support for P4, studies using neurophysiological measurements have shown that the announcement of the auction outcome can trigger a range of different immediate emotions with varying intensities.

While overall studies have shown that the emotions in response to winning an auction are experienced more strongly than those of losing an auction, both for sealed-bid (Astor et al. 2013a; Teubner et al. 2015; van den Bos et al. 2013) and ascending clock auctions (Adam et al. 2015), it is important to note that this is not the case for descending clock auctions. Specifically, Adam et al. (2012) found that in descending clock ("Dutch") auctions the skin conductance responses triggered in response to losing are stronger than those in response to winning. The authors explained this with the "click-to-win" characteristic of Dutch auctions, where losing comes as an unpleasant surprise. Further, pointing to the importance of the "social competition" (Delgado et al. 2008) inherent to auctions, immediate emotions in response to auction outcome are stronger when competing with a human opponent than they are when competing with computerized bidders (Adam et al. 2015; Teubner et al. 2015).

A different perspective on winning and losing is to consider whether the bidder could have achieved a more favorable result had they placed a slightly different bid. The immediate emotions associated with these ex-post considerations are referred to as winner regret and loser regret (Engelbrecht-Wiggans and Katok 2008). Winner regret refers to the notion that the bidder could have still won the auction but achieved a higher profit by placing a slightly lower bid. By contrast, loser regret refers to the notion that the bidder lost the auction but could have won the auction with a profit by placing a slightly higher bid. Note that such regret can only occur in first-price auctions, where bidders have to pay what they bid. Astor et al. (2011) were able to show based on skin conductance measurements that both of these events induce immediate emotions and that, as predicted by Engelbrecht-Wiggans and Katok (2008), loser regret is experienced more strongly than winner regret. However, the results of Astor et al. (2011) also show that the intensity of immediate emotions increases the closer the bidder's successful bid was to the second highest bid. This finding is in conflict with Engelbrecht-Wiggans and Katok's (2008) assumptions underlying the concept of winner regret and instead is more congruent with an emotion of winner relief (Astor et al. 2011). 


\section{Discussion}

By facilitating the exchange of products and services, electronic auctions have become an important element of an increasingly digitized economy. In order to effectively utilize electronic auctions, system designers need to have a profound understanding of how the design of the auction environment affects human bidding behavior and auction outcomes. This requires taking into account not only the cognitive aspects of human bidding behavior but also aspects associated with human affect. The conceptual work by Adam et al. (2011b) attempted to capture how human affective processing may affect a bidder's emotional state and the emergence of immediate emotions during auction participation. Since then, a set of empirical studies have employed neurophysiological measurements to evaluate specific links in the emotional bidding framework for a range of different auction mechanisms.

In the present chapter, we have linked the results of these empirical studies back to the original framework and found support for its four main propositions. Specifically, studies found that both integral (e.g., clock speeds) and incidental factors (e.g., affective imagery) in the auction environment may affect a bidder's emotional state, which in turn affects their bidding behavior. Depending on the auction mechanisms and the type of product being sold, higher arousal may result in higher or lower prices. Further, placing a bid in an auction is an event that triggers immediate emotions, with higher amounts of money yielding stronger intensities. Finally, both winning and losing an auction trigger immediate emotions, the intensities of which depend on the auction mechanism, the type of interaction partner, and the amount of money at stake. Taken together, these findings show that the design of an electronic auction has a significant impact on the affective processes that bidders experience and the impact that this has on bidding behavior and auction outcomes.

Building on these insights, researchers have not only investigated how to design information systems in order to carry out auctions electronically, but also explored how to assist bidders during auction participation, e.g., by predicting auction outcomes based on psychophysiological measurements (Müller et al. 2016). Conceptually, user assistance systems in this context build on the notion of supporting bidders in regulating the emergence of arousal as well as its impact on decision making (Lux et al. 2018; Morana et al. 2020). For instance, system designers can employ biofeedback to support bidders in recognizing and regulating their own physiological arousal levels while participating in an auction (Astor et al. 2013b; Jerčić et al. 2012). There is reason to believe that these systems will become more effective with the increasing ability of machine learning to detect human emotional states based on biosensors. Specifically, the application of deep learning in affective computing has led to strong improvements in the automatic recognition of human emotions from a range of modalities (Rouast et al. 2020). It has also been shown that artificial intelligence can be used to identify psychophysiological features which contribute to a better prediction of bidding behavior (Müller et al. 2016). In this vein, 
leveraging the interplay of human and artificial intelligence, user assistance systems may support bidders in overcoming the detrimental impacts of auction fever.

\section{References}

Adam, M. T. P. (2010). Measuring Emotions in Electronic Auctions. Karlsruhe, DE: KIT Scientific Publishing.

Adam, M. T. P., Gamer, M., Krämer, J., \& Weinhardt, C. (2011a). Measuring emotions in electronic markets. In ICIS 2011 Proceedings (pp. 1-19). Shanghai, CN.

Adam, M. T. P., Krämer, J., Jähnig, C., Seifert, S., \& Weinhardt, C. (2011b). Understanding auction fever: A framework for emotional bidding. Electronic Markets, 21(3), 197-207. https://doi.org/ 10.1007/s12525-011-0068-9

Adam, M. T. P., Krämer, J., \& Weinhardt, C. (2012). Excitement up! Price down! Measuring emotions in Dutch auctions. International Journal of Electronic Commerce, 17(2), 7-40. https:/ /doi.org/10.2753/jec1086-4415170201

Adam, M. T. P., Krämer, J., \& Müller, M. B. (2015). Auction fever! How time pressure and social competition affect bidders' arousal and bids in retail auctions. Journal of Retailing, 91(3), 468485. https://doi.org/10.1016/j.jretai.2015.01.003

Adam, M. T. P., Astor, P. J., \& Krämer, J. (2016). Affective images, emotion regulation and bidding behavior: An experiment on the influence of competition and community emotions in Internet auctions. Journal of Interactive Marketing, 35(1), 56-69. https://doi.org/10.1016/ j.intmar.2015.12.002

Adam, M. T. P., Eidels, A., Lux, E., \& Teubner, T. (2017). Bidding behavior in Dutch auctions: Insights from a structured literature review. International Journal of Electronic Commerce, 21(3), 363-397. https://doi.org/10.1080/10864415.2016.1319222

Adam, M. T. P., Ku, G., \& Lux, E. (2019). Auction fever: The unrecognized effects of incidental arousal. Journal of Experimental Social Psychology, 80(1), 52-58. https://doi.org/10.1016/ j.jesp.2018.07.009

Ariely, D., \& Simonson, I. (2003). Buying, bidding, playing, or competing? Value assessment and decision dynamics in online auctions. Journal of Consumer Psychology, 13(1-2), 113-123. https://doi.org/10.1207/S15327663JCP13-1\&2_10

Astor, P. J., Adam, M. T. P., Jähnig, C., \& Seifert, S. (2011). Measuring regret: Emotional aspects of auction design. In ECIS 2011 Proceedings (pp. 1129-1140). Helsinki, FN.

Astor, P. J., Adam, M. T. P., Jähnig, C., \& Seifert, S. (2013a). The joy of winning and the frustration of losing: A psychophysiological analysis of emotions in first-price sealed-bid auctions. Journal of Neuroscience, Psychology, and Economics, 6(1), 14-30. https://doi.org/10.1037/a0031406

Astor, P. J., Adam, M. T. P., Jerčić, P., Schaaff, K., \& Weinhardt, C. (2013b). Integrating biosignals into information systems: A NeuroIS tool for improving emotion regulation. Journal of Management Information Systems, 30(3), 247-278. https://doi.org/10.2753/MIS0742-1222300309

Bradley, M. M. (2007). Emotion and motivation. In L. G. Tassinary \& G. G. Berntson (Eds.), Handbook of Psychophysiology (pp. 602-642). Cambridge, UK: Cambridge Univ. Press.

Carare, O., \& Rothkopf, M. (2005). Slow Dutch auctions. Management Science, 51(3), 365-373. https://doi.org/10.1287/mnsc. 1040.0328

Delgado, M. R., Schotter, A., Ozbay, E. Y., \& Phelps, E. A. (2008). Understanding overbidding: Using the neural circuitry of reward to design economic auctions. Science, 321(5897), 18491852. https://doi.org/10.1126/science. 1158860

Engelbrecht-Wiggans, R., \& Katok, E. (2008). Regret and feedback information in first-price sealed-bid auctions. Management Science, 54(4), 808-819. 
Hariharan, A., Adam, M. T. P., Teubner, T., \& Weinhardt, C. (2016). Think, feel, bid: The impact of environmental conditions on the role of bidders' cognitive and affective processes in auction bidding. Electronic Markets, 26(4), 339-355. https://doi.org/10.1007/s12525-016-0224-3

Hariharan, A., Adam, M. T. P., Dorner, V., Lux, E., Müller, M. B., Pfeiffer, J., \& Weinhardt, C. (2017). Brownie: A platform for conducting NeuroIS experiments. Journal of the Association for Information Systems, 18(4), 264-296. https://doi.org/10.17705/1jais.00457

Jerčić, P., Astor, P. J., Adam, M. T. P., Hilborn, O., Schaaff, K., Lindley, C., . . Eriksson, J. (2012). A serious game using physiological interfaces for emotion regulation training in the context of financial decision-making. In ECIS 2012 Proceedings (pp. 1-14). Barcelona, ES.

Jung, D., Adam, M. T. P., Dorner, V., \& Hariharan, A. (2017). A practical guide for human lab experiments in information systems research: A tutorial with Brownie. Journal of Systems and Information Technology, 19(3/4), 228-256. https://doi.org/10.1108/JSIT-06-2017-0049

Katok, E., \& Kwasnica, A. M. (2008). Time is money: The effect of clock speed on seller's revenue in Dutch auctions. Experimental Economics, 11(4), 344-357. https://doi.org/10.1007/s10683007-9169-X

Ku, G., Malhotra, D., \& Murnighan, J. K. (2005). Towards a competitive arousal model of decisionmaking: A study of auction fever in live and Internet auctions. Organizational Behavior and Human Decision Processes, 96(2), 89-103. https://doi.org/10.1016/j.obhdp.2004.10.001

Lux, E., Adam, M. T. P., Dorner, V., Helming, S., Knierim, M. T., \& Weinhardt, C. (2018). Live biofeedback as a user interface design element: A review of the literature. Communications of the Association for Information Systems, 43(1), 257-296. https://doi.org/10.17705/ 1CAIS.04318

McAfee, R. P., \& McMillan, J. (1987). Auctions and bidding. Journal of Economic Literature, 25(2), 699-738.

Morana, S., Pfeiffer, J., \& Adam, M. T. P. (2020). User assistance for intelligent systems. Business \& Information Systems Engineering, 1-4. https://doi.org/10.1007/s12599-020-00640-5

Müller, M. B., Adam, M. T. P., Cornforth, D. J., Chiong, R., Krämer, J., \& Weinhardt, C. (2016). Selecting physiological features for predicting bidding behavior in electronic auctions. In HICSS 2016 Proceedings (pp. 396-405). https://doi.org/10.1109/HICSS.2016.55

Murnighan, J. K. (2002). A very extreme case of the dollar auction. Journal of Management Education, 26(1), 56-69. https://doi.org/10.1177/105256290202600105

Myers, D. G. (2004). Psychology (7th ed.). New York, NY, USA: Worth Publishers.

Rick, S., \& Loewenstein, G. (2008). The role of emotion in economic behavior. In M. Leis, J. M. Haviland-Jones, \& L. F. Barrett (Eds.), Handbook of Emotions (pp. 138-156). New York, NY, USA: The Guilford Press.

Riedl, R., Davis, F. D., \& Hevner, A. R. (2014). Towards a NeuroIS research methodology: Intensifying the discussion on methods, tools, and measurement. Journal of the Association for Information Systems, 15(10), i-xxxv.

Rouast, P. V., Adam, M. T. P., \& Chiong, R. (2020). Deep learning for human affect recognition: Insights and new developments. IEEE Transactions on Affective Computing, 1-20. https:// doi.org/10.1109/TAFFC.2018.2890471

Russel, J. (1980). A circumplex model of affect. Journal of Personality and Social Psychology1, 39(6), 1161-1178.

Sigmund, K., Fehr, E., \& Nowak, M. A. (2002). The economics of fair play. Scientific American, 286(1), 82-87.

Smith, K., \& Dickhaut, J. (2005). Economics and emotion: Institutions matter. Games and Economic Behavior, 52(2), 316-335. https://doi.org/10.1016/j.geb.2004.06.017

Teubner, T., Adam, M. T. P., \& Riordan, R. (2015). The impact of computerized agents on immediate emotions, overall arousal and bidding behavior in electronic auctions. Journal of the Association for Information Systems, 16(10), 838-879. https://doi.org/10.17705/1jais.00457

van den Bos, W., Talwar, A., \& McClure, S. M. (2013). Neural correlates of reinforcement learning and social preferences in competitive bidding. Journal of Neuroscience, 33(5), 2137-2146. https://doi.org/10.1523/JNEUROSCI.3095-12.2013

Zajonc, R. B. (1984). On the primacy of affect. American Psychologist, 39(2), 117-123. 
Marc T. P. Adam is an associate professor of Computing and Information Technology at the University of Newcastle, Australia. In his research, he investigates the interplay of users' cognition and affect in human-computer interaction. In 2006, he completed an undergraduate degree in Computer Science from the University of Applied Sciences Würzburg-Schweinfurt, Germany. In 2010, he received a PhD in Information Systems from Karlsruhe Institute of Technology, Germany, supervised by Christof Weinhardt. He is a founding member of the Society for NeuroIS. His research has been published in top international outlets such as IEEE Journal on Biomedical and Health Informatics, IEEE Transactions on Affective Computing, the Journal of the Association for Information Systems, the Journal of Management Information Systems, and the Journal of Retailing.

Jan Krämer is a full professor of Information Systems and holds the chair of Internet and Telecommunications Business at the University of Passau, Germany. He is also an academic co-director at the Centre on Regulation in Europe (CERRE), a Brussels-based think tank. His current research interests include predominantly the regulation of telecommunications and Internet markets, as well as digital ecosystems and data-driven business models. Previously, he headed a research group on telecommunications markets at the Karlsruhe Institute of Technology (KIT), where he also obtained a diploma in Business and Economics Engineering (2005) with a focus on computer science, telematics, and operations research, and a $\mathrm{PhD}$ in Economics (2007), both with distinction. In 2013 he received a habilitation degree from KIT under the supervision of Christof Weinhardt. His research has been published in top-ranked scholarly journals of Information Systems, Marketing, and Economic Regulation, such as Management Science, Information Systems Research, the Journal of Retailing, and the Journal of Industrial Economics. Furthermore, he is the editor and author of several interdisciplinary books on the regulation of telecommunications markets, associate editor of the journal Business \& Information Systems Engineering, and a member of the editorial board of the journals Review of Network Economics and Telecommunications Policy. Krämer has served as academic consultant for leading firms in the telecommunications and Internet industry, as well as for governmental institutions, such as the German Federal Ministry for Economic Affairs and the European Commission.

Open Access This chapter is licensed under the terms of the Creative Commons Attribution 4.0 International License (http://creativecommons.org/licenses/by/4.0/), which permits use, sharing, adaptation, distribution and reproduction in any medium or format, as long as you give appropriate credit to the original author(s) and the source, provide a link to the Creative Commons license and indicate if changes were made.

The images or other third party material in this chapter are included in the chapter's Creative Commons license, unless indicated otherwise in a credit line to the material. If material is not included in the chapter's Creative Commons license and your intended use is not permitted by statutory regulation or exceeds the permitted use, you will need to obtain permission directly from the copyright holder.

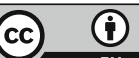

